\title{
EDITORIAL
}

\section{FRAILTY AND COGNITIVE DECLINE: LINKS, MECHANISMS AND FUTURE DIRECTIONS}

\author{
B. SHATENSTEIN
}

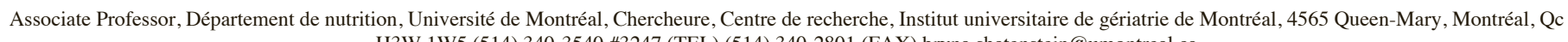
H3W 1W5 (514) 340-3540 \#3247 (TEL) (514) 340-2801 (FAX) bryna.shatenstein@umontreal.ca

The accelerated aging of the population is a worldwide phenomenon resulting from decreases in the birth rate and increased longevity largely due to improved health care. It has led to a striking shift in the population pyramid in most industrialised countries, with the lower-income countries rapidly following suit. It is estimated that some $16 \%$ of the world's population will be aged 65 or over by the year 2050, with the fastest growing segment being those aged 80 and older (1).

While aging is notable for its heterogeneity, a substantial proportion of older adults will experience declines in their physical or cognitive capacities due to the physiological, psychological and social changes that occur with aging. The incidence and prevalence of cognitive decline, dementia and other neurodegenerative diseases are expected to rise with these demographic and age-related changes, leading to a substantially increased burden for caregivers of affected individuals and consequences for their care.

The term "frailty" is widely-used to characterise older adults who are at risk of falls, comorbidities, disability and mortality (2). In their seminal work, Fried et al. (2) characterised frailty in community-dwelling older adults as a physical phenotype based on five physical conditions - weight loss, exhaustion, weakness, slow gait speed and low levels of physical activity; an older adult is considered frail when at least three of these conditions are present. The Fried phenotype has informed much research and clinical practice since its publication. While increasing frailty in community-dwelling older adults has a clear impact on autonomy and may lead to institutionalisation, limited research has been devoted to cognitive dysfunction as a component of frailty, or its consequences among frail older adults in institutions or in long-term care settings.

A search of the literature published in the last 10 years using the keywords "frail elderly" produced almost 4,000 papers reporting on a variety of related issues. However, despite many years of research in this area, and the proposal of numerous frailty criteria and models to refine the definition of the syndrome, clinicians and researchers have been unable to agree on a clear definition of frailty (3). Recent work has shown that diminished cognitive status is associated with physical frailty, and suggests that the addition of cognitive status to the set of frailty characteristics will improve prediction of progression to disability (e.g. 4-7).
In light of recent literature showing links between physical and cognitive frailty, a call for papers was launched in the spring of 2010 in preparation of a special issue of the Journal of Nutrition, Health and Aging on the theme of Frailty and Cognitive Decline. We invited researchers with expertise in the areas of frailty, sarcopenia, body composition and functional decline and in their relationships to cognitive decline and dementia, to submit reports of original research or review papers to this thematic issue of JNHA. In this issue of the Journal, we have gathered an impressive array of papers from research scientists and clinicians working in seven different countries. The work they present has a broad reach and includes a critical review on models of frailty (8), two reports on longitudinal research $(9,10)$, two retrospective database studies on data gathered in the institutional setting (11) and from a population survey (12), a cross-sectional, community-based study (13), and an analysis of the predictive ability of different frailty indices carried out in large cohort of hospitalized patients (14).

These papers provide convincing evidence of links between the frailty phenotype and cognition. They underscore the multidimensional nature of frailty and its components by providing evidence for the role of markers of inflammation and age-related decreases in production of sex hormones and concomitant differences in the expression of frailty between males and females, and by raising questions about changes in muscle mass and strength and the development of sarcopenia in the frailty syndrome. It is still unknown whether frailty precedes dementia or if cognitive dysfunction and physical frailty occur synergistically, and most authors contend that existing frailty indices perform poorly.

There is still much work to be done, but the authors of the papers presented in this issue have provided suggestions for future directions in a number of areas related to frailty. They recommend that a multidisciplinary approach must be taken in the evaluation and care of frail older adults, taking specific population attributes into consideration as these factors could facilitate or protect against the progression to frailty.

\section{References}

1. World Population Ageing. Department of Economic and Social Affairs, Population Division, United Nations, New York, 2009. www.un.org/esa/population/publications/ WPA2009/WPA2009-report.pdf 


\section{FRAILTY AND COGNITIVE DECLINE: LINKS, MECHANISMS AND FUTURE DIRECTIONS}

2. Fried LP, Tangen CM, Walston J, Newman AB, Hirsch C, Gottdiener J, Seeman T, Tracy R, Kop WJ, Burke G, McBurnie MA; Cardiovascular Health Study Collaborative Research Group. Frailty in older adults: evidence for a phenotype. J Gerontol A Biol Sci Med Sci. 2001;56(3):M146-156.

3. van Kan GA, Rolland Y, Houles M, Gillette-Guyonnet S, Soto M, Vellas B. The assessment of frailty in older adults. Clin Geriatr Med. 2010;26(2):275-286.

4. Rockwood K, Howlett SE, MacKnight C, Beattie BL, Bergman H, Hébert R, et al. Prevalence, attributes, and outcomes of fitness and frailty in community dwelling older adults: Report from the Canadian Study of Health and Aging. J Gerontol A Biol Sci Med 2004;Sci 59A: 1310-1317.

5. Rockwood K. Frailty and its definition: a worthy challenge. J Am Geriatr Soc. 2005;53: 1069-1010.

6. Rockwood K, Song X, MacKnight C, Bergman H, Hogan DB, McDowell I, et al. A global clinical measure of fitness and frailty in elderly people. Can Med Assoc J. 2005;173: 489-495.

7. Ávila-Funes JA, Amieva H, Barberger-Gateau P, Le Goff M, Raoux N, Ritchie K, et al. Cognitive impairment improves the predictive validity of the phenotype of frailty for adverse health outcomes: the Three-City Study. J Am Geriatr Soc. 2009;57: 453461.

8. Panza F, V. Solfrizzi, V. Frisardi, S. Maggi, D. Sancarlo, F. Addante, G. D'Onofrio, D. Seripa, A. Pilotto. Different Models of Frailty in Predementia and Dementia Syndromes. J Nutr Health Aging 2011;15(8):711-719.

9. Auyeung T.W., J.S.W. Lee, T. Kwok, J. Woo. Physical Frailty Predicts Future
Cognitive Decline - A Four-Year Prospective Study in 2737 Cognitively Normal Older Adults. J Nutr Health Aging 2011;15(8):690-694.

10. Jacobs J.M., A. Cohen, E. Ein-Mor, Y. Maaravi, J. Stessman. Frailty, Cognitive Impairment and Mortality Among The Oldest Old. J Nutr Health Aging 2011;15(8):678-682.

11. Wirth R, C. Smoliner, C.C. Sieber, D. Volkert. Cognitive Function is Associated with Body Composition and Nutritional Risk of Geriatric Patients. J Nutr Health Aging 2011;15(8):706-710.

12. Canon M.E., E.M. Crimmins. Sex Differences in the Association between Muscle Quality, Inflammatory Markers, and Cognitive Decline. J Nutr Health Aging 2011;15(8):695-698.

13. Ávila-Funes J.A., S.D. Pina-Escudero, S. Aguilar-Navarro, L.M. Gutierrez-Robledo, L. Ruiz-Arregui, H. Amieva. Cognitive Impairment and Low Physical Activity are the Components of Frailty More Strongly Associated with Disability. J Nutr Health Aging 2011;15(8):683-689.

14. Drame M., J.-L. Novella, D. Jolly, I. Laniece, D. Somme, D. Heitz, J.-B. Gauvain, T. Voisin, B. De Wazieres, R. Gonthier, C. Jeandel, P. Couturier, O. Saint-Jean, J. Ankri, F. Blanchard, P.-O. Lang. Rapid Cognitive Decline, One-Year Institutional Admission and One-Year Mortality: Analysis of the Ability to Predict and Inter-Tool Agreement of Four Validated Clinical Frailty Indexes in the Safes Cohort. J Nutr Health Aging 2011;15(8):699-705. 